\title{
Missing Possible Connections between Basic Research and Clinical Reality: Early Detection of Cancer as a Case In Point \\ Michael Retsky*
}

Harvard School of Public Health, 665 Huntington Avenue, Boston, MA 02115, USA

\section{Editorial}

Those of us who are involved in bioequivalence and bioavailability often long for new technologies and techniques for analysis of tissue and fluids and resulting information content for a variety of diseases. We often look to funded biological and medical research for useful developments. Much of the government funded research is toward basic research but it is well recognized that in the long run practical developments often are born out of basic research. My research is very basic but different field of using computer simulation to study tumor growth in breast cancer. I began by studying clinical data and together with colleagues eventually proposed a new and revolutionary concept of how tumors enlarge in size over time. This has led to very promising ideas on how to treat early stage breast cancer [1]. However, I really don't want to focus on that. Rather I want to discuss what I observed and later thought about after attending a small research seminar at one of the major Boston research institutes. There are important lessons from my experience that need to be passed on to young basic researchers.

One of the researchers at this seminar was discussing his work using the TRAMP animal model of prostate cancer. This is a hot field in cancer research and much good work is underway. He was in a very good department under guidance of a distinguished cancer biologist and the laboratory was well funded. The speaker was very smart and knew his subject well. At the end, I asked him if his work might relate to recent reports that early detection of prostate cancer has been found to often lead to significant side effects and unexpectedly small benefits. Many physicians are now recommending watchful waiting rather than treatment for biopsy proven prostate cancer [2-4]. This is a dramatic development in clinical prostate cancer and change from well established practice for two decades. The speaker did not know what I was talking about. He knew nothing at all about the topic. I don't think this is unusual. I am certainly not being critical of that particular researcher but maybe the program needs to be restructured so that basic researchers are at least somewhat acquainted with clinical reality.

Basic researchers, you are missing a great opportunity! Starting in about 1990, the measurement of prostate specific antigen (PSA) in blood was used as a means to detect the presence of cancer cells in the prostate and initiate intervention. Incidence of prostate cancer shot up as expected but surprisingly mortality from prostate cancer increased as well. We have a situation where cancer is detected by no special means and there are many years of detection, relapse, and mortality data. Now we perturb the system in that now cancer is detected at an earlier time using various technologies. What is the result? The expected result is that outcome improves across the board. Nobody suffers any harm. Perhaps not all gain, but many do. That is what is expected according to the accepted paradigm. But what actually happens? Are results consistent with expectations? If so we can assume our understanding of the biology of the disease is on course. But what if expectations are not realized? What then? It means the prostate cancer paradigm is frankly wrong and many thousands of men have been given inappropriate health care. It can be described as a scandal. We are obliged to reexamine the accepted understanding of the biology of the disease. This major opportunity that resulted from a change in clinical practice does not happen often. We must take advantage of the situation.

The best information I have seen is that 1400 men need to be screened for 10 years in order to save one life and in the process 48 men are over diagnosed. Treatment for prostate cancer can often have severe side effects including impotence and incontinence. You should read the literature and make your own interpretation.

How can someone doing research on prostate cancer (with taxpayer money) not know this? You never know if there is some important clinical observation that could be explained by your basic research. In the process, the worst that can happen is that you will learn about the clinical disease and there will be no correlation to your research.

My advice is to put on hip boots and get a big shovel. Dig into the clinical findings and examine the data. I can tell you from the similar situation with mammography, depending on your perspective it is both ugly and beautiful. If you want definite answers, it is ugly. But if you want to hear all the arguments and why such and such data is hopelessly flawed, it is beautiful. Read both sides of the arguments. They are typically very polarized. Each side will present all the arguments for or against any of the many aspects of data or assumptions underlying early detection.

The fundamental problem is that the benefits are small - of the order of $0.1 \%$. They have to screen roughly 1000 persons for years to save one life. That means we need to worry about harms at the $0.1 \%$ level and data are extremely weak at that level. Small changes in assumptions can make large changes in the risk/benefit ratio.

This is a researcher's goldmine plus a very effective learning tool. To understand clinical trials of early detection, you need to know the full spectrum of the disease. Supposedly healthy persons are recruited, they are sent for early detection procedure, and suspicious cases are sent for diagnostic workup. Biopsies are done if cancer is suspected, pathology is used to determine if there is cancer or a benign state, confirmed cases are sent to surgeon, then on to a medical oncologist who will provide adjuvant therapy to reduce chances of relapse and

*Corresponding author: Michael Retsky, Harvard School of Public Health 665 Huntington Avenue, Boston, MA 02115, USA, Tel: 617-432-3472; E-mail: michael.retsky@gmail.com

Received August 30, 2012; Accepted August 31, 2012; Published September 04, 2012

Citation: Retsky M (2012) Missing Possible Connections between Basic Research and Clinical Reality: Early Detection of Cancer as a Case In Point. J Bioequiv Availab 4: xxv-xxvi. doi:10.4172/jbb.10000e21

Copyright: () 2012 Retsky M. This is an open-access article distributed under the terms of the Creative Commons Attribution License, which permits unrestricted use, distribution, and reproduction in any medium, provided the original author and source are credited. 
Citation: Retsky M (2012) Missing Possible Connections between Basic Research and Clinical Reality: Early Detection of Cancer as a Case In Point. J Bioequiv Availab 4: xxv-xxvi. doi:10.4172/jbb.10000e21

then to follow-up for years afterwards. For all these situations, there must be equal representation in intervention and control arms. In order to understand clinical trials of early detection, the researcher may have to become somewhat knowledgeable on all these subjects. Early detection seems on the surface to be a simple no-brainer. But that is not the case at all.

I suggest cancer researchers, especially those working on animal models and/or cell lines make a point to study the real thing for an hour or two a month. It will entail reading papers and attending local hospital tumor boards where individual cases are reviewed in all clinical detail and you will see oncologist's present different opinions on how a particular patient gets treated. It is fascinating and provides a good window into the complex and imperfect world of clinical oncology. This is nothing like your laboratory where you can control the temperature, food consumed, exercise, treatment and everything else that the animal experiences. The real world of clinical cancer is quite another thing.

From my experience, I could tell you that you will surely get a much better understanding of cancer and you may even solve a clinical riddle. It is worth a few days of reading papers and reviews of why prostate cancer early detection did not work out. There are many commercial interests involved in screening for prostate cancer. Beware that some papers will have biases but that is part of clinical oncology. It is all part of the learning process.

\section{References}

1. Retsky M, Rogers R, Demicheli R, Hrushesky WJ, Gukas I, et al. (2012) NSAID analgesic ketorolac used perioperatively may suppress early breast cancer relapse: particular relevance to triple negative subgroup. Breast Cancer Res Treat 134: 881-888.

2. Barry MJ (2009) Screening for prostate cancer--the controversy that refuses to die. N Engl J Med 360: 1351-1354.

3. http://www.cancer.gov/cancertopics/pdq/screening/prostate/ HealthProfessional/page3

4. D'Amico AV, Smith MR (2012) Clinical decisions. Screening for prostate cancer. N Engl J Med 367: e11. 